\title{
Curcumin and zinc co-supplementation along with a loss-weight diet can improve lipid profiles in subjects with prediabetes: a multi-arm, parallel-group, randomized, double-blind placebo-controlled phase 2 clinical trial
}

Majid Karandish', Hassan Mozaffari-khosravi², Seyed Mohammad Mohammadi ${ }^{3}$, Bahman Cheraghian ${ }^{4}$ and Maryam Azhdari ${ }^{*^{*}}$ (1)

\begin{abstract}
Background: Diabetes is one of the major public health concerns. Prediabetes can increase the risk of developing some non-communicable diseases such as type 2 diabetes. Given the increasing trend of prediabetes, it is critical to control it and prevent its complications. Curcumin is a major bioactive component of turmeric. Zinc is an antioxidant nutrient. The present trial aimed to evaluate the effect of curcumin and zinc co-supplementation along with a lossweight diet on serum lipid profiles in overweight or obese patients with prediabetes.

Methods: Eighty-four participants were randomized to four groups (curcumin (500 mg/day), zinc (30 mg/day), "curcumin and zinc", and placebo) for 90 days. Serum total cholesterol (TC), low-density lipoprotein (LDL), high-density lipoprotein (HDL), triglycerides (TG), non-HDL, HDL/LDL ratio, weight, BMI, waist circumstance (WC), hip circumstance $(\mathrm{HC})$, physical activity (PA) and dietary intake were determined pre and post-intervention. This study will be conducted at Yazd Diabetes Research Clinic, Shahid Sadoughi University of Medical Sciences.

Results: Totally, 82 participants were included in the final analysis. After the adjusted PA effect, changes in serum TG (adjusted $p=0.001$ ), LDL (adjusted $p=0.035$ ), non-HDL (adjusted $p=0.003$ ), HDL/LDL ratio (adjusted $p=0.002$ ), and HDL (adjusted $p<0.0001$ ) revealed a significant difference between the groups. However, the changes in weight (adjusted $p=0.004$ ) and BMI (adjusted $p=0.006$ ) were significant but the changes in dietary intake, PA, WC, and HC were non-significant (adjusted $p \geq 0.05$ ). Despite that there was a significant difference for post-intervention $\mathrm{HDL}$ levels (adjusted $p=0.016$ ), other lipid profiles showed no significant difference (adjusted $p \geq 0.05$ ).
\end{abstract}

Conclusion: The beneficial effects of "curcumin and zinc" co-supplementation was reported for the changes of some lipid profiles (TG, LDL, HDL, non-HDL, and HDL to LDL ratio), BMI, and weight with no positive effects on TC,

*Correspondence: azhdari_mar@yahoo.com

2 Department of Nutrition, School of Public Health, Shahid Sadoughi

University of Medical Sciences and Health Services, Yazd, Iran

Full list of author information is available at the end of the article

(c) The Author(s) 2022. Open Access This article is licensed under a Creative Commons Attribution 4.0 International License, which permits use, sharing, adaptation, distribution and reproduction in any medium or format, as long as you give appropriate credit to the original author(s) and the source, provide a link to the Creative Commons licence, and indicate if changes were made. The images or other third party material in this article are included in the article's Creative Commons licence, unless indicated otherwise in a credit line to the material. If material is not included in the article's Creative Commons licence and your intended use is not permitted by statutory regulation or exceeds the permitted use, you will need to obtain permission directly from the copyright holder. To view a copy of this licence, visit http://creativecommons.org/licenses/by/4.0/. The Creative Commons Public Domain Dedication waiver (http://creativeco mmons.org/publicdomain/zero/1.0/) applies to the data made available in this article, unless otherwise stated in a credit line to the data. 
dietary intake, PA, WC, and HC. Therefore, it may play a potential role in the prevention of macro and microvascular complications.

Trial registration The project is a registered clinical trial (Registration number: IRCT20190902044671N1, Iranian Registry of Clinical Trials (IRCT), registered October 11, 2019.

Keywords: Curcumin, Zinc, Dietary intake, Liver enzymes, Lipid profiles, Prediabetes

\section{Introduction}

Prediabetes status is defined as impaired glucose tolerance (IGT), impaired fasting glucose (IFG), and/or $\mathrm{HbA}_{1} \mathrm{C}$ 5.7-6.4\% [1]. Some complications of prediabetes include macrovascular (cardiovascular disease (CVD), stroke, peripheral artery disease), microvascular (retinopathy, neuropathy, and nephropathy), and type 2 diabetes mellitus (T2DM) $[1,2]$. The prevalence of prediabetes among some populations was related to abdominal or visceral obesity, dyslipidemia with high triglycerides (TG), high low-density lipoprotein cholesterol (LDL-C), high total cholesterol (TC), low high-density lipoprotein-cholesterol (HDL-C), and/or hypertension [1, 3, 4]. Moreover, the high prevalence of obesity, dyslipidemia, and T2DM along with cardiovascular complications was reported in the past decade. The physiological, metabolic, or/and biochemical characteristics are abnormal in prediabetic patients. Since the adverse changes in both lipid and glucose concentrations were reported in prediabetes and T2DM, the target of the novel therapeutic approaches is the simultaneous improvement of glucose and lipid control. Therefore, early diagnosis and effective intervention are critical to control prediabetes and delay its complications [5]. Physical activity (PA) and dietary modifications can consider as the key lifestyle interventions. The pharmacological interventions usually apply in prediabetic patients without a positive response to lifestyle interventions [2]. Recent researches have shown too much attention to phytochemicals and the antioxidant trace elements to treat and control some diseases (T2DM, prediabetes, metabolic syndrome, CVD, and chronic venous insufficiency (CVI)) [6-11].

Curcumin (diferuloylmethane) is a bioactive constituent of Curcuma longa L. (Zingiberaceae), commonly known as turmeric with diverse pharmacological and biological properties [7]. Curcumin has shown beneficial effects on glycemic parameters (fasting plasma glucose (FPG), 2-h postprandial (2hpp), $\mathrm{HbA}_{1} \mathrm{C}$, insulin, insulin sensitivity (IS) and insulin resistance (IR)) in prediabetic patients [11], lipid profiles (TG, TC, LDL-C, and HDL-C) and blood pressure (BP) in T2DM [8] and metabolic syndrome [6]. The finding of a meta-analysis of randomized controlled trials showed curcumin may play a protective role in patients at risk of CVD by improving serum lipid levels [10].
Zinc is a trace element that has health benefits in the various aspects of metabolism through antioxidant and anti-inflammatory properties, and cofactor of many enzymes [12-14]. Zinc apart from its role in improving glycemic markers in patients with prediabetes [11] and T2DM [15], plays a notable role in lipid metabolism [16] that can control CVD, one of the current complications in prediabetes and diabetes. However, the findings of some trials or meta-analyses of trials indicated that zinc supplementation improves some lipid profiles, some studies did not show it [17-19].

On the one hand, the results of the effect of curcumin or zinc were inconsistent in previous studies, and on the other hand, there was no trial with aim of evaluating the effect of curcumin and zinc co-supplementation on lipid profiles in prediabetic patients. The present multi-arm, parallel-group, randomized, double-blind placebo-controlled phase 2 clinical trial aimed to evaluate the effect of curcumin and zinc co-supplementation along with lossweight diet on serum lipid profiles (TG, LDL, HDL, TC, non-high-density lipoprotein cholesterol (non-HDL), and HDL to LDL ratio) in overweight or obese patients with prediabetes.

\section{Methods}

The details of the method and materials were previously published [20].

\section{Participants and sampling}

All 84 eligible prediabetic adults with written informed consent were recruited from Yazd Diabetes Research Clinic and enrolled in the present randomized, clinical trial (RCT) for 90 days. The inclusion criteria were included women or men (18-50 years old for men and 18 years- before menopause for women) with prediabetes according to the ADA guidelines [1] and $25<\mathrm{BMI}>35$. Patients were excluded from the trial if a diagnosis of any types of malignancies/cancers, cardiovascular, kidney, lung, endocrine, autoimmune, inflammatory, and neurological diseases, and/ or hypertension, taking BP, glucose or lipid-lowering drugs; taking multivitamin-mineral supplements for three months before or during the intervention; a history of weight loss surgery in the last year, a weight-loss plan in the last 3 months; receiving from a weight-loss medicine or program; lactating, pregnant or 
planning to get pregnant; unwillingness/the compliance of less than $80 \%$ during the intervention, or no signed informed consent.

Considering that the present study was a part of comprehensive research, the sample size was measured for all variables and the largest sample size was considered. The sample size was calculated using both WinPepi statistical program (Version 11.4: Abramson, 2011) and a parallel design randomized controlled trial formula (formula was previously published) [20]. Twenty-one participants in each group were required ( $80 \%$ power at 0.05 significance level and accounting for a drop-out rate of 10\%) [20].

\section{Study setting and design}

This multi-arm, parallel-group, randomized, doubleblind, placebo-controlled, phase 2 clinical trial was reported according to the CONSORT statement (Consolidated Standards for Reporting Trials). The method of block randomization with a block size of 4 using a computer-generated random number sequence and the allocation concealment (assigning the unique codes to the eligible participant) by a blinded independent statistician and the pharmacist (who was not involved during the study), respectively. All the assessments in the trial were made by the investigators blinded to the treatment allocation. The participants were not informed about the type of supplement. The supplements were delivered to the participants according to the allocation on the 1st, 30th, and 60th day.

The eligible participants were randomized into four parallel groups, (1) the curcumin group: curcumin supplement (500 mg-BCM95/ Curcugreen capsule, M/s Arjuna Natural Pvt Ltd., India) and placebo for zinc (lactose); (2) the zinc group: zinc supplement (30 $\mathrm{mg}$ zinc in form of zinc gluconate tablet, Dineh company, Iran) and the placebo for curcumin (roasted rice powder); (3) the "curcumin \& zinc" group: both a curcumin capsule and a zinc tablet; (4) the placebo group: both a placebo capsule for curcumin and a placebo tablet for zinc. Dosages were selected based on the previous studies [21, 22]. The placebo was identical in texture, weight, and appearance to its active supplement. A curcumin capsule (supplement or placebo) and a zinc tablet (supplement or placebo) were prescripts once daily after and before breakfast for 90 days, respectively. All participants have followed a standard, individualized hypo-caloric diet designed with at least a $7 \%$ weight loss including $45-55 \%, 25-35 \%$, and $10-20 \%$ of their calories from carbohydrate, fat, and protein, respectively, and PA for 150 min per week for improving lifestyle. The nutritional modifications, including adherence to the diet and avoiding excessive intake of high-fat and/or sugar products, were recommended by a nutritionist.
This trial was approved by the Medical Ethics Committee of Ahvaz Jundishapur University of Medical Sciences, Ahvaz, Iran; (Ethical code: IR.AJUMS. REC.1398.504) and it is prospectively registered in the Iranian Registry of Clinical Trials (Registration number: IRCT20190902044671N1).

\section{Follow-up}

In order to control the participants for taking supplements and placebo, they were followed up using messaging tools or the telephone, daily or weekly. The lifestyle modifications were individually recommended for all participants who were visited at the end of 30-day periods. Moreover, pill counts were recorded every 30 days to assess adherence to the supplement. All adverse events were documented and reported to the Data Monitoring Committee and the Ethics Committee of the Ahvaz Jundishapur University of Medical Sciences.

\section{Data collection and outcome measures}

The general demographic and medical history data (age, gender, education levels, duration of prediabetes, and family history of prediabetes or hypertension) were obtained from each participant by interview. The measurement of weight and height were recorded to assess body mass index (BMI) $\left(\mathrm{kg} / \mathrm{m}^{2}\right)$ which was calculated by this equation: weight $(\mathrm{kg}) /$ height $\left(\mathrm{m}^{2}\right)$. The waist and hip circumstances were assessed by a non-elastic and flexible tape.

The short form of the International Physical Activity Questionnaire (IPAQ-SF) was used for the evaluation of PA. PA was reported as metabolic equivalents (METs)minutes per week (MET-min/week) and categorized into three groups including active (PA $>3000$ MET-min/ week), moderate (PA $=600-3000 \mathrm{MET}-\mathrm{min} /$ week), and inactive (PA $<600$ MET-min/week) [23].

Diastolic Blood Pressure (DBP) and Systolic Blood Pressure (SBP) were measured at the baseline of the study according to the American Heart Association protocol (blood pressure was assessed in a quiet place after $5 \mathrm{~min}$ of rest in sitting status without crossed legs and unsupported back and arms) [24]. The side effects of supplements were recorded during the study and also liver enzymes were evaluated to monitor possible side effects of supplements.

Blood samples were collected in an EDTA tube and centrifuged to obtain serum. Serum TG, HDL, TC, FPG (mg/dL) levels, HbA1C (\%), alanine transaminase (ALT), and aspartate transaminase (AST) were measured immediately after sampling. The values of non-HDL, HDL/ LDL ratio, and LDL-C were calculated by the following the formula: TC minus HDL-C, HDL (mg/dL) divided 
by LDL $(\mathrm{mg} / \mathrm{dL})$, and Friedewald formula (TC $(\mathrm{mg} /$ $\mathrm{dL})-\mathrm{HDL}-\mathrm{c}(\mathrm{mg} / \mathrm{dL})-\mathrm{TG}(\mathrm{mg} / \mathrm{dL}) / 5)$, respectively [25].

The outcomes included serum lipid profiles and anthropometric measurements which were measured at the baseline and day 90 after the intervention.

\section{Statistical analysis}

All analyses were performed using a statistical software package (SPSS), version 22.0 (SPSS, Inc, Chicago, Illinois, USA). Statistical significance was determined at $\mathrm{p}<0.05$. Normal distribution and the homogeneity of variances for quantitative variables were checked by KolmogorovSmirnov test and Leven's tests, respectively. Data were reported as mean \pm standard deviation (SD) and median (interquartile range) for normally and non-normally distributed data, respectively. Within-group comparisons were performed using a paired-samples t-test. Betweengroup comparisons for variables were carried out using a one-way ANOVA with a post hoc (LSD) analysis test and Kruskal-Wallis for normally and non-normally distributed data, respectively. The changes (pre-post intervention) were calculated based on the difference of variables from the baseline (pre-intervention) to the end (post-intervention) of the study. However, there was no significant difference for pre-intervention, post-intervention, [11] and changes of dietary intake (Additional file 1: Table A2), a significant difference was previously reported in PA levels at the baseline and changes in BMI and weight. Therefore, the adjustment was applied using univariate analysis of covariance (ANCOVA) and a general linear model to control the effects of the baseline PA or/and changes of BMI and weight from the baseline.

\section{Results}

A total of 82 participants completed the 90 days of the trial. Two patients lost the follow-up due to poor compliance and nausea and severe abdominal pain in the "curcumin and zinc" and placebo group (1 patient in each group), respectively. Figure 1 showed the flow diagram of the study. The mild side effects including headache $(n=2)$ in curcumin group, headache $(n=1)$ in zinc group, headache $(\mathrm{n}=1)$, nausea $(\mathrm{n}=2)$, dizziness $(\mathrm{n}=1)$ in "curcumin and zinc" group, and headache $(\mathrm{n}=1)$, nausea $(n=1)$, hearing impairment $(n=1)$ in placebo group were reported by the participants.

The mean duration of prediabetes (months) and age (year) of participants was reported $2.31 \pm 1.37$ and $36.04 \pm 6.61$, respectively. As set out in Table 1, the general and clinical characteristics of the participants were not found any significant difference between the four groups at the baseline except PA levels $(\mathrm{p}=0.03)$. Moreover, there was no significant difference in pre-intervention biochemical measurements of the participants between groups (Additional file 1: Table A1).

For data with both adjusted and crude analyses, only adjusted analyses were reported. Please refer to tables for crude analysis. No significant difference was shown for changes (pre-post) in dietary intake (energy, protein, carbohydrate, and fat) (adjusted $\mathrm{p} \leq 0.05$ ) (Additional file 1: Table A2).

The comparison of changes in liver enzymes, anthropometry measurements, and physical activity was depicted in Table 2. The changes in AST, ALT, WC, HC, and PA were non-significant after adjusting the baseline PA effect (adjusted $\mathrm{p} \geq 0.05$ ). After removing PA effects, the changes in weight and BMI were significant (adjusted $\mathrm{p}=0.004$ and 0.006 , respectively). In comparison to the placebo, all three groups receiving the supplement showed significant differences for the changes in weight and BMI after adjusting PA effects (Additional file 1: Table A3).

The comparison of lipid profiles within and between groups was depicted in Table 3. Moreover, the results of the pairwise comparisons of serum lipid profiles for ANOVA and ANCOVA were shown the Additional file 1: Table A3.

As set out in Table 3 (within-group comparisons), curcumin, zinc, and "curcumin and zinc" groups revealed a significant improvement for post-intervention serum lipid profiles.

The placebo group showed a notable difference in post intervention TG $(\mathrm{p}=0.001), \mathrm{HDL}, \mathrm{HDL} / \mathrm{LDL}$ ratio $(\mathrm{p} \leq 0.001)$, and non-HDL $(\mathrm{p}=0.009)$ without any significant difference in TC $(\mathrm{p}=0.155)$ and LDL $(\mathrm{p}=0.103)$ levels (Table 3 ).

There was no significant difference in pre-intervention lipid profiles between the four groups.

After removing cofounders' effects (baseline PA and changes in BMI and weight), a remarkable difference was found only for post intervention HDL (adjusted $\mathrm{p}=0.016$ ) between groups, without any significant difference for post-intervention TG (adjusted $\mathrm{p}=0.286$ ), non-HDL (adjusted $\mathrm{p}=0.34$ ), LDL (adjusted $\mathrm{p}=0.378$ ), TC (adjusted $\mathrm{p}=0.583$ ), and HDL/ LDL ratio (adjusted $\mathrm{p}=0.132$ ) between groups (Table 3 ).

Serum HDL levels significantly increased in the curcumin (adjusted $\mathrm{p}=0.002$ ), zinc (adjusted $\mathrm{p}=0.016$ ), and "curcumin and zinc" (adjusted $\mathrm{p}=0.015$ ) groups compared to the placebo group after adjusting cofounders' effects (Additional file 1: Table A3).

After removing the confounders' effect (baseline PA and changes in BMI and weight), the changes of all lipid profiles (pre-post) including serum TG 


\section{CONSORT 2010 Flow Diagram}

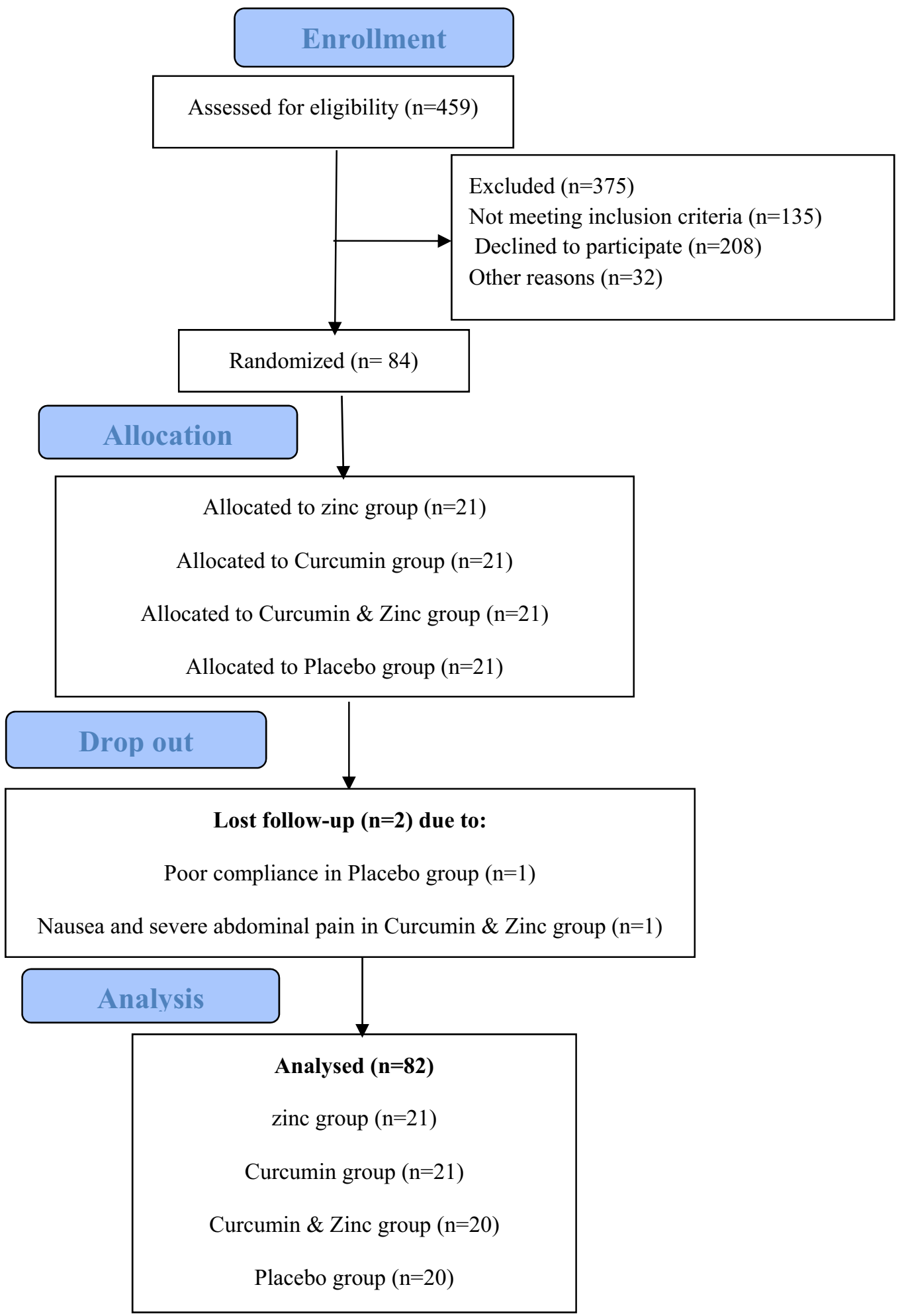

Fig. 1 Consolidated Standards of Reporting Trials (CONSORT) flow chart- trial protocol 
Table 1 General and Clinical characteristics of the participants at the baseline

\begin{tabular}{|c|c|c|c|c|c|}
\hline \multirow[t]{2}{*}{ Variables } & \multicolumn{4}{|l|}{ Groups } & \multirow[t]{2}{*}{ P-value } \\
\hline & $\begin{array}{l}\text { Placebo } \\
\mathrm{N}=\mathbf{2 0}\end{array}$ & $\begin{array}{l}\text { Curcumin } \\
N=21\end{array}$ & $\begin{array}{l}\text { Zinc } \\
N=21\end{array}$ & $\begin{array}{l}\text { Curcumin and Zinc } \\
N=20\end{array}$ & \\
\hline \multicolumn{6}{|l|}{ Qualitative variables } \\
\hline Age (year) & $34.19 \pm 7.03$ & $36.95 \pm 7.23$ & $38.19 \pm 4.87$ & $34.48 \pm 6.45$ & 0.14 \\
\hline Weight (kg) & $84.67 \pm 9.78$ & $82.6 \pm 8.03$ & $81.81 \pm 13.08$ & $80.57 \pm 10.17$ & $0.65^{*}$ \\
\hline Body mass index $\left(\mathrm{kg} / \mathrm{m}^{2}\right)$ & $30.97 \pm 2.33$ & $30.46 \pm 2.75$ & $29.5 \pm 2.82$ & $29.95 \pm 2.56$ & $0.32^{*}$ \\
\hline Waist circumstance $(\mathrm{cm})$ & $108.01 \pm 10.18$ & $107.44 \pm 9.9$ & $103.39 \pm 11.75$ & $106.77 \pm 10.19$ & $0.493^{*}$ \\
\hline Hip circumstance $(\mathrm{cm})$ & $111.76 \pm 7.16$ & $112.47 \pm 6.84$ & $109.79 \pm 6.04$ & $108.88 \pm 5.15$ & $0.242^{*}$ \\
\hline Physical activity & $445(396-853.88)$ & $990(495-1860)$ & $396(396-1440)$ & $396(396-982)$ & $0.03^{\#}$ \\
\hline Systolic blood pressure (mmHg) & $110.56 \pm 9$ & $117.7 \pm 6.9$ & $115.7 \pm 7.8$ & $114.5 \pm 8.2$ & 0.437 \\
\hline Diastolic blood pressure $(\mathrm{mmHg})$ & $70.43 \pm 4.3$ & $75 \pm 3.6$ & $73 \pm 5.1$ & $73.3 \pm 4.2$ & 0.644 \\
\hline Fat $(g r)$ & $30.47 \pm 3.85$ & $32.03 \pm 3.42$ & $32.03 \pm 3.6$ & $30.25 \pm 4.1$ & $0.26^{*}$ \\
\hline \multicolumn{6}{|l|}{ Quantitative variables } \\
\hline Gender (female) & $12(60)$ & $16(76.2)$ & $15(71.5)$ & $13(65)$ & $0.837^{\#}$ \\
\hline \multicolumn{6}{|l|}{ Education levels } \\
\hline University education & $10(50)$ & $14(66.7)$ & $12(57.1)$ & $12(60)$ & $0.585^{\#}$ \\
\hline Diploma & $6(30)$ & $6(28.6)$ & $4(19.1)$ & $6(30)$ & \\
\hline Under diploma & $4(20)$ & $1(4.8)$ & $5(23.8)$ & $2(10)$ & \\
\hline
\end{tabular}

Data are presented as mean \pm standard deviation (SD) for quantitative variables and frequency (\%) for qualitative variables

* P-value was calculated for the comparison variables between four groups using one-way analysis of variance (one-way ANOVA)

\# P-value was calculated for the comparison variables between four groups using Kruskal-Wallis

P-value $<0.05$ was considered significant

Table 2 Comparison of changes $\mathbf{m}$ in liver enzymes, anthropometry measurements, and physical activity between the groups

\begin{tabular}{|c|c|c|c|c|c|c|}
\hline \multirow[t]{2}{*}{ Variables } & \multicolumn{4}{|l|}{ Groups } & \multirow[t]{2}{*}{ p } & \multirow[t]{2}{*}{ Adjusted $\mathrm{P}^{*}$} \\
\hline & $\begin{array}{l}\text { Placebo } \\
\mathrm{N}=\mathbf{2 0}\end{array}$ & $\begin{array}{l}\text { Curcumin } \\
N=21\end{array}$ & $\begin{array}{l}\text { Zinc } \\
N=21\end{array}$ & $\begin{array}{l}\text { Zinc and curcumin } \\
\mathrm{N}=20\end{array}$ & & \\
\hline Alanine transaminase (IU/L) & $-0.7 \pm 2.96$ & $-1.05 \pm 3.93$ & $-1.19 \pm 3.17$ & $-1.1 \pm 3.23$ & 0.968 & 0.918 \\
\hline Aspartate transaminase (IU/L) & $0.05 \pm 2.48$ & $-0.8 \pm 2.48$ & $-0.09 \pm 2.39$ & $0 \pm 3.31$ & 0.708 & 0.426 \\
\hline Weight (kg) & $-2.59 \pm 2.45$ & $-4.88 \pm 3.14^{b}$ & $-4.88 \pm 2.63^{b}$ & $-5.79 \pm 2.77^{c}$ & 0.004 & 0.004 \\
\hline Body mass index $\left(\mathrm{kg} / \mathrm{m}^{2}\right)$ & $-0.92 \pm 0.85$ & $-1.96 \pm 1.299^{b}$ & $-1.85 \pm 1.01^{b}$ & $-2.09 \pm 1.17^{c}$ & 0.004 & 0.006 \\
\hline Waist circumstance (cm) & $-1.86 \pm 2.12$ & $-3.84 \pm 2.86$ & $-2.95 \pm 3.35$ & $-3.16 \pm 2.55$ & 0.154 & 0.26 \\
\hline Hip circumstance $(\mathrm{cm})$ & $-2.345 \pm 2.01$ & $-4.83 \pm 4.16$ & $-4.08 \pm 4.08$ & $-4.94 \pm 3.37$ & 0.081 & 0.161 \\
\hline Physical activity $\left(M E T \cdot m i n \cdot w^{-1}\right)$ & $22.75(-74.25,346)$ & $49.5(-738.75,426)$ & $-213(-213,346.5)$ & $198(-178.5,532)$ & 0.763 & 0.98 \\
\hline
\end{tabular}

MET.min $\cdot \mathrm{wk}^{-} 1$ : metabolic equivalent of task minute per week

Data were presented as mean \pm standard deviation or median (interquartile (IQR)) for normally and non-normally distributed data, respectively

-The changes (pre-post intervention) calculated based on the difference of variables from the baseline (pre- intervention) to the end (post intervention) of the study $P$ was calculated for the comparison variables between four groups using one-way analysis of variance (one-way ANOVA) with post hoc (LSD) analysis

\# $P$ was calculated for the comparison variables between four groups using Kruskal-Wallis

* Adjusted P-value was calculated using ANCOVA or nonparametric ANCOVA; Adjusted for physical activity levels at the baseline Significant changes with placebo group indicated by ${ }^{a} p<0.05,{ }^{b} p<0.01,{ }^{c} p<0.001$

(adjusted $\mathrm{p}=0.001$ ), LDL (adjusted $\mathrm{p}=0.035$ ), HDL (adjusted $\mathrm{p} \leq 0.001$ ), non-HDL (adjusted $\mathrm{p}=0.003$ ), and HDL/LDL ratio (adjusted $\mathrm{p}=0.002$ ) except serum $\mathrm{TC}$ (adjusted $\mathrm{p}=0.15$ ) showed a significant difference between four groups. In comparison to the placebo group, three supplement groups sustained a remarkable improvement for LDL, HDL, non-HD, and HDL/ LDL ratio after removing the cofounders' effects. The p-values were depicted in Additional file 1: Table A3. After removing the cofounders' effects, changes 
Table 3 Comparisons of lipid profiles of the participants between and within the groups

\begin{tabular}{|c|c|c|c|c|c|c|}
\hline \multirow[t]{2}{*}{ Variables } & \multicolumn{4}{|l|}{ Groups } & \multirow[t]{2}{*}{ p-value } & \multirow{2}{*}{$\begin{array}{l}\text { Adjusted } \\
\text { p-value* }\end{array}$} \\
\hline & $\begin{array}{l}\text { Placebo } \\
(\mathrm{N}=20)\end{array}$ & $\begin{array}{l}\text { Curcumin } \\
(\mathrm{N}=21)\end{array}$ & $\begin{array}{l}\text { Zinc } \\
(\mathrm{N}=21)\end{array}$ & $\begin{array}{l}\text { Zinc and curcumin } \\
(\mathrm{N}=20)\end{array}$ & & \\
\hline \multicolumn{7}{|l|}{ Triglyceride (mg/dl) } \\
\hline Pre-intervention & $132.55 \pm 25.96$ & $131.48 \pm 26.16$ & $125.76 \pm 25.74$ & $126.1 \pm 27.64$ & 0.776 & - \\
\hline Post-intervention & $123.1 \pm 18.6$ & $107.48 \pm 11.9$ & $114.52 \pm 16.93$ & $111.6 \pm 18.01$ & 0.026 & 0.286 \\
\hline P-value & 0.001 & $<0.001$ & 0.001 & $<0.001$ & - & - \\
\hline Change & $-9.45 \pm 10.51$ & $-24.0 \pm 18.97^{b}$ & $-11.24 \pm 13.821$ & $-14.50 \pm 12.094$ & 0.007 & 0.001 \\
\hline \multicolumn{7}{|c|}{ Total cholesterol (mg/dl) } \\
\hline Pre-intervention & $186.5 \pm 24.91$ & $188.95 \pm 23.5$ & $182.52 \pm 26.11$ & $181.35 \pm 19.98$ & 0.716 & - \\
\hline Post-intervention & $184.25 \pm 24.4$ & $175.71 \pm 17.01$ & $172.67 \pm 21.34$ & $170.95 \pm 13.45$ & 0.146 & 0.583 \\
\hline P-value & 0.103 & $<0.001$ & 0.001 & $<0.001$ & - & - \\
\hline Change & $-2.25 \pm 5.87$ & $-13.24 \pm 11.52$ & $-9.86 \pm 10.94$ & $-10.40 \pm 9.98$ & 0.005 & 0.15 \\
\hline \multicolumn{7}{|l|}{ LDL (mg/dl) } \\
\hline Pre-intervention & $111.74 \pm 22.29$ & $114.63 \pm 20.22$ & $110.81 \pm 28.22$ & $110.87 \pm 20.53$ & 0.944 & - \\
\hline Post-intervention & $109.48 \pm 22.77$ & $97.74 \pm 18.9$ & $94.86 \pm 23.78$ & $92.93 \pm 15.65$ & 0.057 & 0.378 \\
\hline P-value & 0.155 & $<0.001$ & $<0.001$ & $<0.001$ & - & - \\
\hline Change & $-2.26 \pm 6.83$ & $-16.89 \pm 11.68^{b}$ & $-15.96 \pm 14.82^{a}$ & $-17.93 \pm 10.06^{a}$ & $<0.001$ & 0.035 \\
\hline \multicolumn{7}{|l|}{$\mathrm{HDL}(\mathrm{mg} / \mathrm{dl})$} \\
\hline Pre-intervention & $48.25 \pm 5.58$ & $47 \pm 6.39$ & $47.14 \pm 6.77$ & $46 \pm 6.37$ & 0.734 & - \\
\hline Post-intervention & $50.15 \pm 5.34$ & $56.47 \pm 6.14^{b}$ & $54.9 \pm 6.8^{\mathrm{a}}$ & $55.7 \pm 6.3^{\mathrm{a}}$ & 0.007 & 0.016 \\
\hline P-value & $<0.001$ & $<0.001$ & $<0.001$ & $<0.001$ & - & - \\
\hline Change望 & $1.90 \pm 1.41$ & $9.48 \pm 4.14^{c}$ & $7.76 \pm 6.40^{c}$ & $9.70 \pm 3.23^{c}$ & $<0.001$ & $<0.001$ \\
\hline \multicolumn{7}{|l|}{ Non-HDL (mg/dl) } \\
\hline Pre-intervention & $138.25 \pm 26.47$ & $141.95 \pm 24.91$ & $135.38 \pm 26.47$ & $135.35 \pm 21.81$ & 0.834 & - \\
\hline Post-intervention & $134.1 \pm 26.47$ & $119.24 \pm 24.91$ & $117.76 \pm 31.79$ & $115.25 \pm 21.81$ & 0.036 & 0.34 \\
\hline P-value & 0.009 & $<0.001$ & $<0.001$ & $<0.001$ & - & - \\
\hline Change= & $-4.15 \pm 6.42$ & $-22.71 \pm 13.27^{c}$ & $-17.62 \pm 15.14^{a}$ & $-20.10 \pm 10.27^{a}$ & $<0.001$ & 0.003 \\
\hline \multicolumn{7}{|l|}{ HDL to LDL ratio } \\
\hline Pre-intervention & $0.45 \pm 0.13$ & $0.42 \pm 0.11$ & $0.47 \pm 0.21$ & $0.43 \pm 0.11$ & 0.712 & 0.192 \\
\hline Post-intervention & $0.48 \pm 0.14$ & $0.6 \pm 0.14$ & $0.63 \pm 0.23$ & $0.62 \pm 0.15$ & 0.025 & 0.132 \\
\hline P-value & $<0.001$ & $<0.001$ & $<0.001$ & $<0.001$ & - & - \\
\hline Change & $-0.03 \pm 0.04$ & $-0.18 \pm 0.1^{c}$ & $-0.16 \pm 0.15^{b}$ & $-0.19 \pm 0.08^{c}$ & $<0.001$ & 0.002 \\
\hline
\end{tabular}

Data were presented as mean \pm standard deviation

$H D L$ high-density lipoprotein-cholesterol, LDL low-density lipoprotein, Non-HDL non-high-density lipoprotein

The changes (pre-post intervention) calculated based on the difference of variables from the baseline (pre- intervention) to the end (post intervention) of the study $\mathrm{P}<0.05$ was considered significant difference

- P-value was calculated for the comparison variables within group using paired t-test

P-value was calculated for the comparison variables between four groups using one-way analysis of variance (one-way ANOVA) with post hoc (LSD) analysis

* Adjusted P-value was calculated using ANCOVA; Adjusted for PA levels at the baseline, changes in BMI and weight

Significant changes with placebo group indicated by adjusted $p<0.05$, ${ }^{b}$ adjusted $p \leq 0.01,{ }^{c}$ adjusted $p \leq 0.001$

(pre-post) in TG were revealed a significant difference only in the curcumin group in comparison to the placebo group (adjusted $\mathrm{p}=0.001$ ).

\section{Discussion}

The main results of the present 90-days trial indicated that there was a significant difference between the groups for (1) the changes in BMI, weight, TG, LDL,
HDL, non-HDL, and HDL/LDL ratio and (2) postintervention HDL. Given that no significant difference for changes in ALT and AST and any reports of severe adverse reactions during the trial, the safety of the prescribed combination was represented.

Despite lifestyle recommendations, hypocaloric diet, and ongoing patient follow-up, the mean decrease in energy in each group was less than 500-1000 kcal (the 
values of recommended) and the changes in PA and dietary intake were not significant between groups, but the change (pre-post intervention) in weight and BMI showed a shift towards their improvement. Therefore, it may emanate from the positive effects of supplements on weight and BMI. It is notable that the undesirable impacts of quarantine on lowering PA cannot be ignored due to the prohibition of leaving home and the closure of gym, fitness and sports club, and park and the restrictions on social activity $[26,27]$.

It seems under the supervision of a nutritionist along with the closure of bars, restaurants, and coffee shops, remote staff, and enough time to prepare foods in the home due to COVID-19 quarantine may have led to the healthy selection of foods (better quality) without the remarkable changes in the amount of food (quantify) which contributed to the improvement of some of serum lipid profiles in the placebo groups.

After adjusting cofounder effects, the post-intervention comparisons of the serum lipid profiles showed there was a significant difference only for serum HDL between groups. This finding can present the important role of cofounders as well as the supplements on serum lipid levels during the intervention.

The progression of prediabetes to T2DM emanates from oncoming disturbed glucose and lipid metabolism [5]. On the other hand, the previous studies illustrated a high prevalence of dyslipidemia in prediabetes and T2DM [3, 4]. However, a correlation was reported between dyslipidemia prevalence with age, sex, education level, smoking status, alcohol drinking status, and obesity [4], the mean of the aforementioned variables was similar among all participants in the present trial. Therefore, the present findings may be related to the effect of the supplements.

As previously published [11], curcumin and zinc cosupplementation significantly improved some glycemic parameters such as IR and IS. Therefore, in addition to their indirect effects on lipid profiles via the improvement of IR and IS, other mechanisms may be illustrated the positive effects of the supplements on the lipid profile.

Given that the control cofounder in the present trial, it can be stated that the studied supplementations were presented the main role in improving the serum lipid profiles.

In agreement with the present results, a meta-analysis (2017) showed curcumin and turmeric decrease the risk factors of CVD through lowering TG and LDL in prediabetes, metabolic syndrome, T2DM, and hypertension [10]. Moreover, a trial conducted by Panahi et al. [8], touched upon an improvement in the changes of serum HDL, TC, and non-HDL and but no significant difference in TG and LDL changes after 1000 mg-curcumin intake in patients with T2DM. In another trial carried out by Thota et al. [28], the curcumin alone (1000 mg) or curcumin $(1000 \mathrm{mg})$ with omega-3 did not alter serum lipid profiles in the patients with IFG and IGT.

In some previous investigations, an improvement in some serum lipid levels (TC, HDL, LDL, and TG) was illustrated following zinc supplementation [15, 17, 18] in different populations. Furthermore, the findings of a meta-analysis conducted by Asbaghi et al. [17] presented the beneficial impacts of zinc supplementation on HDL in both studies duration less or more than 12-weeks. Also, zinc supplementation decreased serum TG, TC, and LDL only in the studies with 12 weeks or less. It is notable that they pointed out the highest impact of zinc supplementation was on a dosage of less than $100 \mathrm{mg}$ [17]. While the present trial did not show the beneficial effects of zinc supplement alone on serum TC and LDL and changes of TG in comparison to the placebo group, zinc supplementation with curcumin improved all serum lipid profiles except serum TC levels compared to the placebo group.

The conflicting findings of zinc or curcumin effects on serum lipid profiles can emanate from bioavailability and dose of the supplement, study duration, variety in the studied population (race, age, sex, history of diseases and etc.), several methodological limitations, the usage of supplement alone or with other nutrients (co-supplementation).

Some mechanisms that can justify the effect of curcumin or zinc supplements are separately described: curcumin can reduce serum TG through the different mechanisms, including increasing the gene expression of adiponectin and peroxisome proliferator-activated receptor alpha (PPAR- $\alpha)$, peroxisome proliferator-activated receptor gamma (PPAR- $\gamma$ ), cholesteryl ester transfers protein, and lipoprotein lipase activity. Curcumin can also reduce serum LDL by suppressing the LDL receptor gene expression through enhancement in PPAR- $\gamma$ activation. In addition, curcumin reduces $\mathrm{TC}$ by affecting enzyme pathways of cholesterol metabolism [29].

Zinc may play effective roles in serum lipid profiles through several molecular mechanisms. The proposed mechanisms of directly and indirectly zinc action are as follows: (1) zinc can affect the activity of pancreatic $\beta$-cells through transporter expression; hence, regulating insulin storage and secretion; (2) zinc can improve insulin sensitivity or insulin resistance through (a) increasing the phosphorylation of insulin-receptor substrates at the adipocytes [12], (b) lipolysis inhibition in adipose tissues, which lead to a decrease in fatty acids released and finally regulate lipoprotein synthesis (VLDL and LDL secretion) from the liver; and (3) zinc can affect the gene expression 
of enzymes involved in hepatic lipid homeostasis leading to regulate lipid synthesis and utilization in mitochondria and peroxisomes [30].

The main limitation of the present trial was the participant recruitment was from single-center and the single dosage of each supplement was used. Further, a part of the research was done during quarantine conditions (COVID-19), the quarantine may have a desirable and undesirable impact on the present trial. The present study is unique in its novelty due to the use of zinc and curcumin co-supplements on serum lipid profiles of prediabetic patients.

It was suggested to conduct further RCTs with regard to the recruitment of patients with a longer history of prediabetes due to the appearance of macro and microvascular complications of prediabetes may need to longer time (the duration mean $(\mathrm{CI})$ of prediabetes diagnosis in this trial was $2.32[2.02,2.62]$ months). Moreover, the serum lipid profiles of participants at the baseline were in the normal range. The different results may find in recruiting the participants with an abnormality in serum lipid profiles at the baseline.

\section{Conclusion}

The present trial was reported the beneficial effects of curcumin and zinc co-supplementation on serum HDL and the changes in serum TG, LDL, HDL, non-HDL, HDL/LDL ratio, BMI, and weight among patients with diabetes. Therefore, it may play a potential role in the prevention of macro and microvascular complications.

It is suggested that multicenter and long-term clinical trials be conducted to confirm the serum lipid-improving properties of curcumin and zinc co-supplements in prediabetic patients with dyslipidemia. Moreover, it recommended examining whether co-administration of curcumin and zinc in other doses and forms can be useful for the prevention of diabetic macro and microvascular complications.

\footnotetext{
Abbreviations

ADA: American Diabetes Association; ALT: Alanine Transaminase; ANCOVA: Analysis of Covariance; AST: Aspartate Aminotransferase; BMI: Body Mass Index; CONSORT: Consolidated Standards for Reporting Trials; DBP: Diastolic Blood Pressure; ELISA: Enzyme-Linked Immunosorbent Assay; FPG: Fasting Plasma Glucose; IPAQ-SF: Short form of International Physical Activity Questionnaire; IQR: Interquartile range; IRCT: Iranian Registry of Clinical Trials; IR: Insulin resistance; IS: Insulin Sensitivity; LDL-C: Low-density lipoprotein cholesterol; MET: Metabolic Equivalent of Task; Non-HDL: Non-high density lipoprotein-cholesterol; One-way ANOVA: One-way Analysis of variance; PA: Physical activity; PPAR-a: Peroxisome proliferator-activated receptor alpha; PPAR-y: Peroxisome proliferator-activated receptor gamma; RCT: Randomized Clinical Trial; SBP: Systolic Blood Pressure; SD: Standard Deviation; SPSS: Statistical Software Package; T2DM: Type 2 Diabetes Mellitus.
}

\section{Supplementary Information}

The online version contains supplementary material available at https://doi. org/10.1186/s13098-022-00792-2.

Additional file 1: Table A1. The biochemical measurements of the participants at the baseline. Table A2. Comparison of changes in liver enzymes, anthropometry measurements, physical activity, and dietary intake between the groups. Table A3. Results of the pairwise comparisons of BMI, weight, and serum lipid profiles for significant ANCOVA.

\section{Acknowledgements}

The authors sincerely thank all patients participating in this study. The authors also extend our appreciation to Dr.Khalilzadeh who was the chief of the Diabetes Research and Clinical Practice Center of Yazd, Iran due to his cooperation in every way possible in this study. The authors are grateful to " $\mathrm{M} / \mathrm{s}$ Arjuna Natural Pvt Ltd., India and "Dineh company, Iran". Moreover, the present manuscript is extracted from Ph.D. thesis of Maryam Azhdari.

\section{Authors' contributions}

MK, HM, and MA participated in study design and protocol development. MA and SMM coordinated recruitment and participant management. SMM confirmed all participants. MA collected data adhering to study protocol. BC provided statistical advice and input. The initial draft was written by MA. All authors read and approved the final manuscript.

\section{Funding}

The project was financially supported by Ahvaz Jundishapur University of Medical Sciences under the research grant number 8913 dated October 20, 2019. The grant covered patient recruitment, manpower, consumables, and other runs in costs for the trial. The funding body did not have any involvement in the study design, the execution, data collection, data analysis, and interpretation, or preparation and publishing of the present manuscript.

\section{Availability of data and materials}

The datasets used and/or analyzed during the current study are available from the corresponding author on reasonable request.

\section{Declarations}

\section{Ethics approval and consent to participate}

This trial was approved by the Medical Ethics Committee of Ahvaz Jundishapur University of Medical Sciences, Ahvaz, Iran (Ethical code: IR.AJUMS. REC.1398.504) in accordance with the ethical standards of the institutional and/or national research committee and with the 1964 Helsinki declaration and its later amendments or comparable ethical standards. The written informed consent was obtained from all patients to participate in this study after receiving a complete explanation of the study protocols and objectives.

\section{Consent for publication}

The authors affirm that human research participants provided informed consent for publication of their data.

\section{Competing interests}

The authors declare no competing interests associated with this publication and there has been no significant financial support for this work that could have influenced its outcome.

\section{Author details}

${ }^{1}$ Nutrition and Metabolic Diseases Research Center, Clinical Sciences Research Institute, Ahvaz Jundishapur University of Medical Sciences, Ahvaz, Iran. ${ }^{2}$ Department of Nutrition, School of Public Health, Shahid Sadoughi University of Medical Sciences and Health Services, Yazd, Iran. ${ }^{3}$ Associate Professor of Endocrinology \& Metabolism, School of Medicine, Shahid Sadoughi University of Medical Sciences and Health Services, Yazd, Iran. ${ }^{4}$ Alimentary Tract 
Research Center, Clinical Sciences Research Institute, Department of Biostatistics and Epidemiology, School of Health Sciences, Ahvaz Jundishapur University of Medical Sciences, Ahvaz, Iran.

Received: 28 September 2021 Accepted: 10 January 2022 Published online: 28 January 2022

\section{References}

1. Classification and Diagnosis of Diabetes. Standards of medical care in diabetes-2020. Diabetes Care. 2020;43(Suppl 1):S14-s31.

2. Mahat RK, Singh N, Arora M, Rathore V. Health risks and interventions in prediabetes: a review. Diabetes Metab Syndr. 2019;13(4):2803-11.

3. Al Amri T, Bahijri S, Al-Raddadi R, Ajabnoor G, Al Ahmadi J, Jambi H, et al. The association between prediabetes and dyslipidemia among attendants of primary care health centers in Jeddah, Saudi Arabia. Diabetes Metab Syndr. 2019;12:2735-43.

4. Li Y, Zhao L, Yu D, Ding G. The prevalence and risk factors of dyslipidemia in different diabetic progression stages among middle-aged and elderly populations in China. PLoS ONE. 2018;13(10): e0205709.

5. Erion DM, Park HJ, Lee HY. The role of lipids in the pathogenesis and treatment of type 2 diabetes and associated co-morbidities. BMB Rep. 2016:49(3):139-48.

6. Azhdari M, Karandish M, Mansoori A. Metabolic benefits of curcumin supplementation in patients with metabolic syndrome: a systematic review and meta-analysis of randomized controlled trials. Phytother Res. 2019;33(5):1289-301.

7. Omosa L, Midiwo J, Kuete V. Curcuma longa. In: Medicinal spices and vegetables from Africa: Therapeutic Potential against Metabolic, Inflammatory, Infectious and Systemic Diseases. Cambridge: Academic Press; 2017;425-35

8. Panahi Y, Khalili N, Sahebi E, Namazi S, Reiner Ž, Majeed M, et al. Curcuminoids modify lipid profile in type 2 diabetes mellitus: a randomized controlled trial. Complement Ther Med. 2017:33:1-5.

9. Azhdari M, Zilaee M, Karandish M, Hosseini SA, Mansoori A, Zendehdel M, et al. Red vine leaf extract (AS 195) can improve some signs and symptoms of chronic venous insufficiency, a systematic review. Phytother Res. 2020;34(10):2577-85. https://doi.org/10.1002/ptr.6705.

10. Qin S, Huang L, Gong J, Shen S, Huang J, Ren H, et al. Efficacy and safety of turmeric and curcumin in lowering blood lipid levels in patients with cardiovascular risk factors: a meta-analysis of randomized controlled trials. Nutr J. 2017;16(1):68.

11. Karandish M, Mozaffari-khosravi H, Mohammadi SM, Cheraghian B, Azhdari $M$. The effect of curcumin and zinc co-supplementation on glycemic parameters in overweight or obese prediabetic subjects: a phase 2 randomized, placebo-controlled trial with a multi-arm, parallel-group design. Phytother Res. 2021. https://doi.org/10.1002/ptr.7136.

12. Lynch CJ, Patson BJ, Goodman SA, Trapolsi D, Kimball SR. Zinc stimulates the activity of the insulin-and nutrient-regulated protein kinase mTOR. Am J Physiol Endocrinol Metab. 2001;281(1):E25-34.

13. Dunn MF. Zinc-ligand interactions modulate assembly and stability of the insulin hexamer-a review. Biometals. 2005;18(4):295-303.

14. Stefanidou M, Maravelias C, Dona A, Spiliopoulou C. Zinc: a multipurpose trace element. Arch Toxicol. 2005;80(1):1.

15. Jayawardena R, Ranasinghe P, Galappatthy P, Malkanthi R, Constantine G, Katulanda P. Effects of zinc supplementation on diabetes mellitus: a systematic review and meta-analysis. Diabetol Metab Syndr. 2012;4(1):13.

16. Choi S, Liu X, Pan Z. Zinc deficiency and cellular oxidative stress: prognostic implications in cardiovascular diseases. Acta Pharmacol Sin. 2018;39(7):1120-32

17. Asbaghi O, Sadeghian M, Fouladvand F, Panahande B, Nasiri M, Khodadost M, et al. Effects of zinc supplementation on lipid profile in patients with type 2 diabetes mellitus: a systematic review and metaanalysis of randomized controlled trials. Nutr Metab Cardiovasc Dis. 2020;30(8):1260-71. https://doi.org/10.1016/j.numecd.2020.03.021.

18. Ranasinghe $P$, Wathurapatha WS, Ishara MH, Jayawardana R, Galappatthy $P$, Katulanda $P$, et al. Effects of zinc supplementation on serum lipids: a systematic review and meta-analysis. Nutr Metab. 2015;12:26.

19. Jafarnejad S, Mahboobi S, McFarland LV, Taghizadeh M, Rahimi F. Metaanalysis: effects of zinc supplementation alone or with multi-nutrients, on glucose control and lipid levels in patients with type 2 diabetes. Prev Nutr Food Sci. 2019;24(1):8-23.

20. Karandish M, Mozaffari-Khosravi H, Mohammadi SM, Azhdari M, Cheraghian B. Evaluation of the effect of curcumin and zinc co-supplementation on glycemic measurements, lipid profiles, and inflammatory and antioxidant biomarkers in overweight or obese prediabetic patients: a study protocol for a randomized double-blind placebo-controlled phase 2 clinical trial. Trials. 2020;21(1):1-11.

21. Panahi Y, Khalili N, Sahebi E, Namazi S, Simental-Mendía LE, Majeed $M$, et al. Effects of curcuminoids plus piperine on glycemic, hepatic and inflammatory biomarkers in patients with type 2 diabetes mellitus: a randomized double-blind placebo-controlled trial. Drug Res. 2018;68(07):403-9.

22. Kim J, Ahn J. Effect of zinc supplementation on inflammatory markers and adipokines in young obese women. Biol Trace Elem Res. 2014;157(2):101-6

23. Craig CL, Marshall AL, Sjöström M, Bauman AE, Booth ML, Ainsworth BE, et al. International physical activity questionnaire: 12-country reliability and validity. Med Sci Sports Exerc. 2003;35(8):1381-95.

24. Pickering T, Hall J, Appel L, Falkner B, Graves J, Hill M, et al. Recommendations for blood pressure measurement in humans. A statement for professionals from the subcommittee of professional and public education of the American Heart Association council on high blood pressure research. Hypertension. 2005;45:142-61.

25. Rifai N, Bachorik PS, Albers JJ. Lipids, lipoproteins and apolipoproteins. Tietz Textb Clin Chem. 1999;3:809-61.

26. Kriaucioniene V, Bagdonaviciene L, Rodríguez-Pérez C, Petkeviciene J. Associations between changes in health behaviours and body weight during the COVID-19 quarantine in Lithuania: the Lithuanian COVIDiet Study. Nutrients. 2020;12(10):3119.

27. López-Sánchez GF, López-Bueno R, Gil-Salmerón A, Zauder R, Skalska $M$, Jastrzębska J, et al. Comparison of physical activity levels in Spanish adults with chronic conditions before and during COVID-19 quarantine. Eur J Public Health. 2020;31(1):161-6. https://doi.org/10.1093/eurpub/ ckaa159.

28. Thota RN, Acharya SH, Garg ML. Curcumin and/or omega-3 polyunsaturated fatty acids supplementation reduces insulin resistance and blood lipids in individuals with high risk of type 2 diabetes: a randomised controlled trial. Lipids Health Dis. 2019;18(1):31

29. Panahi Y, Ahmadi Y, Teymouri M, Johnston TP, Sahebkar A. Curcumin as a potential candidate for treating hyperlipidemia: a review of cellular and metabolic mechanisms. J Cell Physiol. 2018;233(1):141-52.

30. Dieck Ht, Döring F, Fuchs D, Roth H-P, Daniel H. Transcriptome and proteome analysis identifies the pathways that increase hepatic lipid accumulation in zinc-deficient rats. J Nutr. 2005;135(2):199-205.

\section{Publisher's Note}

Springer Nature remains neutral with regard to jurisdictional claims in published maps and institutional affiliations.

Ready to submit your research? Choose BMC and benefit from

- fast, convenient online submission

- thorough peer review by experienced researchers in your field

- rapid publication on acceptance

- support for research data, including large and complex data types

- gold Open Access which fosters wider collaboration and increased citations

- maximum visibility for your research: over 100M website views per year

At BMC, research is always in progress.

Learn more biomedcentral.com/submissions 